Gut, 1972, 13, 610-613

\title{
Chronic hepatitis and cirrhosis of the liver in cryoglobulinaemia
}

\author{
G. P. JORI AND G. BUONANNO
}

From the Institute of Medical Pathology I, University of Naples, and the Haematological Division, Ospedale S. Gennaro, Naples

SUMMARY Hepatic biopsy showed either persistent or aggressive chronic hepatitis in 11 patients with cryoglobulinaemia not attributable to known disease entities, whereas liver impairment was not in every case suggested by either physical examination or functional abnormalities. The incidence was predominantly in women and cryoglobulin behaviour was similar in these patients and in five subjects with cirrhosis-associated cryoglobulinaemia. It is concluded that liver disease should be included among the constant features of the cryoglobulin-associated syndrome, and the speculation is advanced that in cryoglobulinaemic patients both cirrhosis and chronic hepatitis may be caused by the same pathogenic mechanism(s).

Cryoglobulinaemia refers to the presence of plasma proteins that reversibly precipitate on cooling. Although most commonly associated with multiple myeloma, macroglobulinaemia, and malignant lymphomas, cryoglobulins have been also encountered in a variety of diseases, including cirrhosis of the liver (Griffiths and Gilchrist, 1953). On the other hand, serum cryoglobulins have been detected in patients who did not fit into any hitherto described clinical entity (Meltzer, Franklin, Elias, McKlusky, and Cooger, 1966), a condition usually (and unsatisfactorily) referred to as 'essential cryoglobulinaemia' (Goldberg and Barnett, 1970). Indeed, hepatosplenomegaly has been so frequently reported in these patients (Costanzi, Coltman, Clark, Tennenbaum, and Criscuolo, 1965; Meltzer et al, 1966; Golde and Epstein, 1968; Feizi and Gitlin, 1969; Mathison, Condemi, Leddy, Callerame, Panner, and Vaughan, 1971) as to suggest the possibility that cryoglobulinaemia could be significantly associated with liver disease(s) other than cirrhosis.

We had the opportunity of studying 11 patients with 'essential cryoglobulinaemia', whose liver histology and function were assessed together with serological abnormalities. We report in this paper the results afforded by this investigation; also, similar studies performed simultaneously in five patients with cryoglobulinaemia and cirrhosis are presented for purposes of comparison.

Received for publication 9 May 1972.

\section{Case Material}

The admitted patients were selected among those proved positive by a screening test for cryoglobulinaemia carried out in our institutions. In none of the patients could either systemic disorders or chronic infections be demonstrated; in fact, after the completion of appropriate diagnostic studies, the patients could be subdivided into two groups according to hepatic biopsy examination as follows.

\section{GROUP A}

Eleven patients had histological evidence of chronic hepatitis (nine females and two males, aged 37 to 60 ). These patients had a combination of clinical features including purpura, arthralgia, and hepatosplenomegaly, whereas overt signs of hepatic dysfunction were either scanty or absent.

\section{GROUP B}

Five patients had histological evidences of hepatic cirrhosis (four females and one male, aged 45 to 63). These patients presented clinical features highly suggestive of severe liver disease, whereas purpura was present in two and arthralgia in one of them.

Although mild to moderate abnormalities were found in the urinary sediment of most patients, overt renal disease was present in only one (no. 9), who had proteinuria, hyperazotaemia, and diastolic hypertension of eight months' duration without any evidence of previous streptococcal infection.

A summary of the clinical diagnoses is given in 


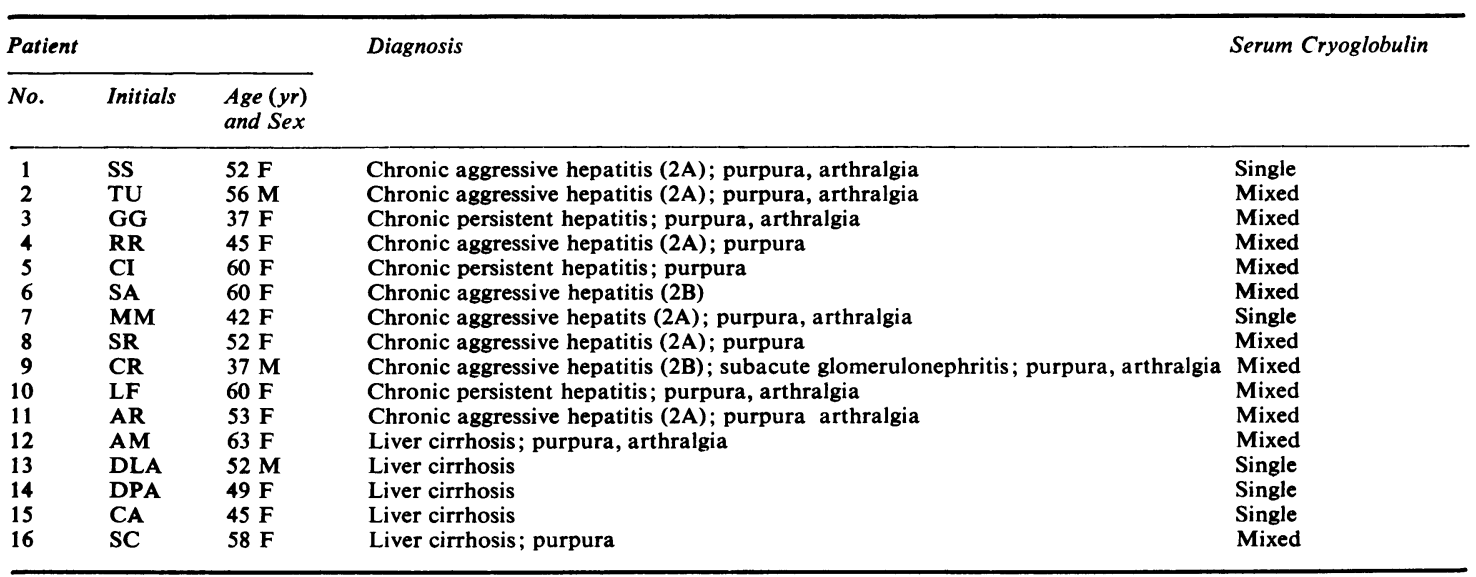

Table I Clinical assessment of 16 patients with cryoglobulinaemia

Table I, which also specifies for each patient whether pure or mixed cryoglobulins were found in the respective sera.

\section{Methods}

Pure cryoglobulin isolation was performed as follows: $20 \mathrm{ml}$ of venous blood from the fasting patient was collected using plastic syringes warmed at $37^{\circ} \mathrm{C}$. The blood was allowed to clot for three hours in a water bath at $37^{\circ} \mathrm{C}$, and thereafter centrifuged for five min at $3000 \mathrm{rpm}$. The supernatant serum was then decanted, and kept at temperatures between $0^{\circ}$ and $4^{\circ} \mathrm{C}$ for 24 hours. Cryoglobulin precipitates were resuspended in cold normal saline, and washed five times at temperatures between $0^{\circ}$ and $4^{\circ} \mathrm{C}$.

The amounts $(\mathrm{mg} / 100 \mathrm{ml})$ of serum cryoglobulin were calculated as the difference between serum total proteins before and after cryoglobulin precipitation.

Immunoelectrophoresis of both sera and cryoglobulin precipitates was done by the micromethod of Scheidegger (1955), employing rabbit and goat antihuman total sera, as well as monospecific sera anti-IgA, anti-IgC, and anti-IgM (Behring-Werke). Moreover, the levels of serum immunoglobulins were assessed by simple radial immunodiffusion, using partigen $\operatorname{IgA}, \operatorname{IgC}$, and IgM; normal ranges for our laboratories had been previously established by studying 75 healthy people, and are expressed as the mean \pm 2 SD.

Tests for rheumatoid factor were performed by latex fixation.

Haematological and liver studies were done by standard procedures. The sera from nine patients (nos. 1, 2, 4, 6, 7, 10, 11, 14, 15) were tested for HAA (hepatitis-associated antigen) with the immunodiffusion method. Three patients (nos. 6, 7, 12) refused bone marrow aspiration, whereas in all of them hepatic biopsy could be performed; the latters however, had to be deferred for two to three months in six patients (nos. $1,3,4,6,7,8$ ) because of a severe bleeding tendency at the time of the initial examination.

\section{Results}

SEROLOGICAL STUDIES (TABLE II)

All the cryoglobulins present in the serum were immunoglobulins. Cryoglobulin amounts greater than $1 \mathrm{~g} \%$ were found in seven patients with chronic hepatitis (nos. 2, 3, 4, 5, 6, 10,11), whereas values less than $1 \mathrm{~g} \%$ were found in four cirrhotics (nos. $13,14,15,16)$. Moreover, those patients with hepatitis had mixed IgC-IgM cryoglobulinaemia, and one of them showed a combination of $\operatorname{IgA}, \mathrm{IgG}$, and IgM cryoglobulins in the cryoprecipitate washed five times. Among the cirrhotics, on the other hand, pure IgG cryoglobulins were found in three subjects (nos. 13, 14, 15), and mixed IgG-IgM cryoglobulins could be detected in the remaining two (nos. 12, 16). However, these differences did not appear to be significant on statistical analysis. Immunoglobulin determination showed that a number of both hepatitic and cirrhotic patients had raised levels of serum IgA and IgG. Although elevated IgA seemed to prevail in patients with hepatitis, statistical analysis showed this to be an erroneous impression. On the contrary, serum IgM was significantly higher in patients with hepatitis than in those with cirrhosis $(\mathrm{P}<0.05)$.

\section{LIVER STUDIES (TABLE III)}

As previously stated, subjective complaints referable to liver disease were almost entirely lacking in 


\begin{tabular}{|c|c|c|c|c|c|}
\hline \multirow[t]{2}{*}{ Patient No. } & \multicolumn{3}{|c|}{ Immunoglobulins $(\mathrm{mg} / 100 \mathrm{ml})$} & \multirow{2}{*}{$\begin{array}{l}\text { Amount of Cryoglobulin } \\
(\mathrm{g} / 100 \mathrm{ml})\end{array}$} & \multirow{2}{*}{$\begin{array}{l}\text { Rheumatoid Factor } \\
\text { (latex fixation) }\end{array}$} \\
\hline & $\operatorname{IgA}($ n.v. $130-400)$ & $\operatorname{Ig} G($ n.v. 800-1800) & $\operatorname{Ig} M($ n.v. 80-190) & & \\
\hline \multicolumn{6}{|c|}{ Patients with IgG } \\
\hline 1 & 408 & 3820 & 155 & $1 \cdot 1$ & Absent \\
\hline 13 & 155 & 1870 & 145 & 0.4 & Absent \\
\hline 14 & 200 & 2800 & 135 & 0.5 & Absent \\
\hline 15 & 944 & 2840 & 164 & $0 \cdot 3$ & Absent \\
\hline \multicolumn{6}{|c|}{ Patients with IgM } \\
\hline 7 & 455 & 2100 & 350 & $0 \cdot 1$ & 80 \\
\hline \multicolumn{6}{|c|}{ Patients with 'mixed' cryoglobulins (IgG and IgM) } \\
\hline 10 & 320 & 2800 & 250 & $1 \cdot 1$ & 1280 \\
\hline 2 & 256 & 1160 & 275 & $1 \cdot 6$ & 640 \\
\hline 4 & 328 & 3280 & 510 & $1 \cdot 2$ & 2560 \\
\hline 5 & 296 & 2600 & 195 & $1 \cdot 3$ & 1280 \\
\hline 6 & 136 & 3080 & 385 & 1.4 & 160 \\
\hline 8 & 656 & 2160 & 220 & 0.2 & 160 \\
\hline $9^{1}$ & (184) & $(760)$ & (25) & $(0 \cdot 3)$ & 80 \\
\hline 12 & 312 & 1920 & 132 & 1.2 & 1280 \\
\hline 16 & 800 & 3000 & 220 & $0 . \overline{2}$ & Absent \\
\hline 11 & 380 & 2200 & 300 & $1 \cdot 4$ & 640 \\
\hline \multicolumn{6}{|c|}{ Patient with 'mixed' cryoglobulins (IgA, $\operatorname{Ig} G$, and $\operatorname{Ig} M)$} \\
\hline 3 & 80 & 1760 & 275 & $2 \cdot 8$ & 2560 \\
\hline
\end{tabular}

Table II General properties of cryoglobulinaemia sera

${ }^{1}$ At the time of this study, case 9 had proteinuria between 5 and $10 \mathrm{~g} / 1$.

\begin{tabular}{|c|c|c|c|c|c|c|c|c|}
\hline Patient No. & $\begin{array}{l}\text { Total Serum } \\
\text { Protein } \\
(\mathrm{g} / 100 \mathrm{ml})\end{array}$ & $\begin{array}{l}\text { Percentage } \\
\gamma \text {-Globulin }\end{array}$ & $\begin{array}{l}\text { Hepato- } \\
\text { splenomegaly }\end{array}$ & $\begin{array}{l}\text { Prothrombin } \\
\text { Time }(\%)\end{array}$ & $\begin{array}{l}\text { BSP } \\
\text { Retention } \\
(\% 45 \text { min })\end{array}$ & $\begin{array}{l}\text { Serum GOT } \\
\text { Transaminase } \\
(U / 100 \mathrm{ml})\end{array}$ & $\begin{array}{l}\text { HAA } \\
\text { Antigen } \\
\text { (immuno- } \\
\text { diffusion } \\
\text { method) }\end{array}$ & $\begin{array}{l}\text { Histological Diagnosis by } \\
\text { Liver Biopsy }\end{array}$ \\
\hline \multicolumn{9}{|l|}{ Group $A$} \\
\hline 1 & $7 \cdot 2$ & 36 & Present & 58 & 16 & 60 & Absent & Chronic aggressive hepatitis (2A) \\
\hline 2 & $7 \cdot 1$ & 33 & Present & 54 & 13 & 80 & Absent & Chronic aggressive hepatitis (2A) \\
\hline 3 & 7.0 & 30 & Absent & 84 & 4 & 47 & $\mathrm{ND}^{1}$ & Chronic persistent hepatitis \\
\hline 4 & $7 \cdot 2$ & 31 & Present & 69 & 10 & 100 & Absent & Chronic aggressive hepatitis (2A) \\
\hline 5 & $7 \cdot 0$ & 32 & Present & 48 & $2 \cdot 5$ & 50 & ND $^{1}$ & Chronic persistent hepatitis \\
\hline 6 & $\mathbf{7 \cdot 4}$ & 28 & Present & 48 & 18 & 60 & Absent & Chronic aggressive hepatitis (2B) \\
\hline 7 & $6 \cdot 7$ & 24 & Absent & 84 & 2 & 30 & Absent & Chronic aggressive hepatitis (2A) \\
\hline 8 & $6 \cdot 4$ & 32 & Present & 55 & 8 & 90 & ND & Chronic aggressive hepatitis (2A) \\
\hline 9 & $5 \cdot 4$ & 13 & Borderline & 75 & 24 & 30 & ND & Chronic aggressive hepatitis (2B) \\
\hline 10 & $7 \cdot 2$ & 34 & Present & 58 & 6 & 55 & Absent & Chronic persistent hepatitis \\
\hline 11 & $6 \cdot \overline{8}$ & 38 & Borderline & 60 & 12 & 40 & Abserit & Chronic aggressive hepatitis (2A) \\
\hline \multicolumn{9}{|l|}{ Group B } \\
\hline & 4.8 & 39 & Present & 24 & 29 & 90 & ND & Liver cirrhosis \\
\hline 13 & 59 & 28 & Present & 29 & 24 & 60 & ND & Liver cirrhosis \\
\hline 14 & 6.7 & 29 & Present & 54 & 21 & 41 & Absent & Liver cirrhosis \\
\hline 15 & $8 \cdot 3$ & 28 & Present & 38 & 17 & 70 & ND & Liver cirrhosis \\
\hline 16 & $7 \cdot 2$ & 28 & Present & 37 & 14 & 51 & Absent & Liver cirrhosis \\
\hline
\end{tabular}

Table III Liver studies

'ND = not done

patients belonging to group $\mathrm{A}$; moreover, medical histories in this connexion were given by all of them. However, liver involvement was suggested by a combination of hepatosplenomegaly, hypergammaglobulinaemia, altered prothrombin time, increased bromsulphalein retention, and raised serum GOT in eight of these subjects (nos. 1, 2, 4, 5, 6, 8, 10, 11), whereas raised gamma globulins on serum paper electrophoresis were the sole abnormality present in two (nos. 3, 7), and the remaining one (no. 9) was normal except for a barely palpable liver and spleen. In none of the tested patients could HAA be demonstrated by the immunodiffusion method.

On the other hand, in all the 11 patients of group A liver biopsy demonstrated the histological landmarks of chronic hepatitis, which were evaluated according to the morphological criteria recently summarized by Popper and Schaffner (1971), and 
classified as recommended by an international committee (de Groote, Demet, Gedigk, Korb, Popper, Poulsen, Scheurer, Schmid, Thaler, Uehlinger, and Wepler, 1968).

In patients of group B the existence of advanced liver impairment could be strongly suspected because of a number of quite characteristic clinical features. Indeed, functional studies were in good agreement with the results of liver biopsies, which demonstrated a cirrhotic process in all of these patients. There were not impressive differences between one biopsy and another, all having in common micronodularity and scattered lymphocytic foci in the parenchyma and portal triads.

\section{Discussion}

Although the pathogenic properties of cryoglobulins cannot be at this time exactly defined, several observations have suggested that these proteins may exert harmful effects on various body tissues. As it is, a clinical syndrome consisting of purpura, arthralgia, and renal disease has been attributed to cryoglobulins since the original report of Meltzer et al (1966). However, hepatosplenomegaly has been a very frequent feature in those patients whose clinical details are available (Costanzi et al, 1965; Meltzer et al, 1966; Golde and Epstein, 1968; Feizi and Gitlin, 1969; Mathison et al, 1971), and in a number of these subjects either liver biopsy or necropsy demonstrated chronic hepatitis (Costanzi et al, 1965; Meltzer et al, 1966; Feizi and Gitlin, 1969). In the present study, histological evidence of chronic hepatitis was disclosed in all of the 11 patients with cryoglobulinaemia not attributable to other underlying disease, whose past medical history did not reveal any previous condition relating to the present liver status. Moreover, three of these patients did not have clear-cut evidence of liver disease, as expressed by either subjective complaints, hepatosplenomegaly, or functional abnormalities. Therefore, it appears from this study that liver involvement may be a constant feature of the cryoglobulin-associated syndrome, ranging in severity from persistent to aggressive chronic hepatitis. Furthermore, the initial transition of the disease process into cirrhosis was suggested by the severity of histological alterations observed in two patients. In this connexion, it should be remembered that the association between cryoglobulinaemia and cirrhosis of the liver has long been recognized. In the present study, the level and composition of serum cryoglobulins did not significantly differ between five cirrhotic patients and those with chronic hepatitis; in addition an impressive preponderance of women and advanced age were features noted in both groups. These data lead us to speculate that the same pathogenic mechanism(s) may cause both kinds of liver disease in cryoglobulinaemic subjects.

\section{References}

Costanzi, J. J., Coltman, C. A., Clark, Jr., D. A., Tennenbaum, J. I., and Criscuolo, D. (1965). Cryobulinemia associated with a macroglobulin. Studies of a $17.5 S$ cryoprecipitating factor. Amer. J. Med., 39, 163-172.

De Groote, J., Desmet, V. J., Gedigk, P., Korb, G., Popper, H., Poulsen, H., Scheuer, P. J., Schmid, M., Thaler, H., Uehlinger, E., and Wepler, W. (1968). A classification of chronic hepatitis. Lancet, 2, 626-628.

Feizi, Ten, and Gitlin, N. (1969). Immune-complex disease of the kidney associated with chronic hepatitis and cryoglobulinaemia. Lancet, 2, 873-976.

Goldberg, L. S., and Barnett, E. V. (1970). Essential cryoglobulinaemia. Immunologic studies before and after penicillamine therapy. Arch. intern. Med., 125, 145-150.

Golde, D., and Epstein, W. (1968). Mixed cryoglobulins and glomerulonephritis. Ann. intern. Med., 69, 1221-1227.

Griffiths, L. L., and Gilchrist, L. (1953). Cryoglobulinaemia in alcoholic cirrhosis. Lancet, 1, 882-884.

Marmont, A., Damasio, E., and Rossi, F. (1967). La crioagglutininemia idiopatica cronica. Atti XXI Congr. Naz. Soc. Ital. Ematol., pp. 227-270.

Mathison, D. A., Condemi, J. J., Leddy, J. P., Callerame, M. L., Panner, B. J., and Vaughan, J. H. (1971). Purpura, arthralgia, and IgM-IgG cryoglobulinaemia with rheumatoid factor activity: response to cyclophosphamide and splenectomy. Ann. intern. Med., 74, 383-390.

Meltzer, M., Franklin, E. C., Elias, K., McClusky, R. T., and Cooper, N. (1966). Cryoglobulinemia. A clinical and laboratory study. II. Cryoglobulins with rheumatoid factor activity. Amer. J. Med., 40, 837-856.

Popper, H., and Schaffer, F. (1971). The vocabulary of chronic hepatitis. New Engl. J. Med., 284, 1154-1156.

Scheidegger. J. J. (1955). Une microméthode de l'immunoelectrophorèse. Int. Arch. Allergy, 7, 103-114.

Wintrobe, M. M. (1967). Clinical Hematology, 6th ed., p. 1202. Lea and Febiger, Philadelphia. 